Cad. Benjaminianos, Belo Horizonte, v. 14, n. 1, p. 87-102, 2018

\title{
Walter Benjamin e Roland Barthes às margens da escritura
}

\section{Walter Benjamin and Roland Barthes on the Banks of Writing}

\author{
Derick Davidson Santos Teixeira \\ Universidade Federal de Minas Gerais (UFMG), Belo Horizonte, Minas Gerais / Brasil \\ derick.davey@gmail.com
}

Resumo: A noção de escritura, desenvolvida por teóricos como Roland Barthes, Jacques Derrida e Maurice Blanchot, no século XX, possui um lugar medular na teoria da literatura e na crítica literária. $O$ presente trabalho propõe um cotejamento entre a teoria de Walter Benjamin e de Roland Barthes no que concerne à escritura. Tomando alguns traços principais da escritura, analisados por Barthes, em conjunto com o pensamento de Benjamin acerca da narração, do declínio da experiencia e de algumas obras da literatura moderna - como a obra de Proust- é possível elucidar de que forma a escritura, operando como um limiar (Schwelle), escapa à rigidez das fronteiras que separam o pessoal e o histórico, a ordem comum do individualismo, a experiência da vivência.

Palavras-chave: Roland Barthes; Walter Benjamin; escritura; limiar.

Abstract: The notion of writing, developed by theorists such as Roland Barthes, Jacques Derrida and Maurice Blanchot, in the 20th century, has a fundamental place when it comes to literary theory and literary criticism. This work proposes a collating between Walter Benjamin's and Roland Barthes' theory concerning writing. Taking some main features of writing, analyzed by Barthes, together with Benjamin's thought about narration, the decline of experience and some modern literary works - such as Proust's oeuvre - it is possible to elucidate how writing, working as a threshold (Schwelle), escapes from the rigidity of the borders that separate the personal and the historical, the common order and individualism, experience and "inner lived experience".

Keywords: Roland Barthes; Walter Benjamin; writing; threshold. 
A teoria da literatura desenvolvida na França, na segunda metade do século XX, é marcada pela basilar noção ${ }^{1}$ de escritura, ${ }^{2}$ cara a pensadores como Roland Barthes, Maurice Blanchot, Jacques Derrida e Michel Foucault. Partamos da constatação de que a escritura é desde sempre da ordem do traço, vestígio, isto é, fragmento, diferente da totalidade épica, e cuja origem histórica não pode ser devidamente localizada, havendo dela somente rastros. ${ }^{3}$ Apesar de sua presença embrionária ao longo dos séculos, o aflorar da escritura se dá, gradualmente, no decorrer do século XVIII e XIX, alcançando seu ápice perceptível nas escritas do século $\mathrm{XX}$, em especial nas vanguardas.

É no século XIX que Barthes localiza uma cena que proponho, aqui, pensar como mito que tenta reparar a origem histórica não localizável da escritura. Segundo o teórico, por volta de 1850, o autor deixa de ser uma testemunha universal para se tornar uma consciência solitária às voltas com a linguagem, dando origem, assim, à escritura. Em texto inspirado pelo pensamento de Marx, Barthes descreve a seguinte imagem:

Começa então a elaborar-se uma ideia imagística do escritorartesão que se encerra num lugar lendário, como um operário que trabalha em casa, e desbasta, talha, dá polimento e incrusta a sua forma, exatamente como um lapidário extrai a arte da matéria, passando nesse trabalho horas regulares de solidão e esforço. (BARTHES, 2000, p. 54).

Para além do que traz sobre o escritor enquanto trabalhador manual, ainda que não restrito ao "pragmatismo da atividade burguesa", como

\footnotetext{
${ }^{1}$ Como esclarece Leyla Perrone-Moisés (2012, p.75) menos que um "conceito (representação mental geral e abstrata de um objeto), trata-se de uma noção (conhecimento sintético intuitivo e impreciso)". Tal noção permite reconhecer em alguns textos um conjunto de traços que os definem como particulares, "sem que esses traços constituam uma totalidade que sirva de modelo". ${ }^{2}$ Sabemos que o francês, ao contrário do português, possui apenas uma única palavra para designar a representação da fala ou do pensamento por meio de sinais: écriture. Para os teóricos que trabalham a escritura, tal prática difere da escrita entendida como mera representação da fala ou daquela estudada pela grafologia, sendo assim, aproveitando a riqueza léxica do Português, o qual possui os vocábulos "escrita" e "escritura" é mais plausível acatar a palavra escritura como forma de diferenciá-la da escrita comum.

${ }^{3}$ Como a Epopeia continha já em si o germe do romance, conforme nos lembra Benjamin em "O narrador", Roland Barthes (1980, p.17) escreve que aquilo que, hoje, chamamos escritura aqui está desde que há grafia, variando apenas seu grau em determinados textos.
} 
escreveu Barthes às voltas com Baudelaire (2000, p. 56), a imagem nos interessa, sobretudo, pelo que condensa acerca da própria escritura. Ao lado do trabalho de incrustação, ilustrando a ampliação da ficcionalização, a qual permite ao escritor, ainda que partindo da realidade, transcendêla, o ofício da escritura se faz, ainda, com um outro movimento: o da extração de excessos. Nesse aflorar da escritura a literatura se torna uma "linguagem consistente, profunda e cheia de segredos, dada ao mesmo tempo como sonho e como ameaça" (BARTHES, 2000, p. 4-5). Retenhamos, dessa imagem, três traços distintivos da escritura: sua origem no indivíduo solitário, sua materialidade, marcada por incrustações e extrações, e seu valor de sonho.

Pensar a escrita como materialidade é elucidar a emergência do peso do significante, em oposição ao prestígio do referente ou significado. Ao contrário da poética clássica, pautada pela retórica, a escritura, como uma poética moderna, atualiza a noção de estilo. Nela não se trata do "estilo chão", baseado na distinção entre fundo e forma, tributário das noções de inventio, dispositio e elocutio, ${ }^{4}$ mas de um "escalonamento de significantes" (BARTHES, 2005, p. 13). Essa prática, ao tomar a palavra como objeto, segundo Barthes, aproxima-se de uma montagem, isto é "escalonamento de significantes" que "dispensa o centro"; nela, o escritor se transforma em "um cenógrafo: aquele que se dispersa através dos bastidores que planta e escalona até o infinito" (BARTHES, 2005, p. 13). Emergindo como poética descentrada, na qual o significante é evidenciado, a escritura coloca em cheque as noções de intenção - ou autoria - e levanta de forma significativa uma discussão acerca da referencialidade da escrita e de suas possíveis relações com a História.

Essa noção barthesiana de uma montagem significante na qual o sujeito que escreve é colocado em dispersão e apagamento, como escreveu Barthes no ensaio seminal "A morte do autor", pode ser cotejada com uma noção de escritura desenvolvida ao longo da obra de Walter Benjamin, embora tal noção não tenha, nele, lugar tão medular quanto aquele que vemos na obra de Barthes. Márcio Seligmann elucida que tal noção, em Benjamin, surge na esteira da constatação de uma "redescrição/ colagem do mundo e da sua história a partir da tarefa imposta pela dupla revolução na técnica e na experiência histórica" (2012, p. 183).

\footnotetext{
${ }^{4}$ Invenção ou escolha dos conteúdos; disposição e organização dos elementos no discurso e elocução adequada ao assunto, respectivamente
} 
Como ele escreve, há para Benjamin, uma "revolução escritural" que "deveria ser acompanhada também de uma revolução na historiografia" (SELIGMANN-SILVA, 2012, p. 183).

A teoria da escritura, em Benjamin, permeia praticamente toda sua obra sendo que, conforme escreve Seligmann, "pode-se dizer grosso modo que ela migra de um acento sobre o teor escritural do mundo (que pode ser lido como um texto) para uma teoria dos sistemas de escritura e do historiador como autor de uma grafia histórica" (2012, p. 184). O crítico escreve, ainda, acerca da importância da teoria do Trauerspiel no desenvolvimento de tal noção, para ele, este estudo leva a uma "teoria da situação do homem moderno", a qual é, nas suas palavras, "a apresentação da fragmentação do mundo simbólico e da sua transformação em ruínas e em alegorias" (SELIGMANN-SILVA, 2012, p. 186). Assim, o que surge na modernidade "é o significante" já que o "significado final e a moral da história, enquanto fórmulas concentradas da cultura pedagógica, estão banidos" (SELIGMANN-SILVA, 2012, p. 186). Benjamin, escreve Seligmann, critica as visões clássicas e científicas segundo as quais a língua é "um instrumento transparente" voltado para a comunicação (2012, p. 192). Nessa perspectiva, para o filósofo alemão, "o mundo linguístico só existe a partir da leitura da arquiescritura" e o trabalho do pensador é o de "traduzir essa escritura fracionada, remontá-la em novos mosaicos" - gênero que Benjamin elegeu para caracterizar o seu trabalho "tratadístico" sobre o Trauerspiel (SELIGMANN-SILVA, 2012, p.192).

Essa reflexão escritural surge, também, segundo o crítico da obra benjaminiana, na leitura da obra de Baudelaire, nas suas anotações sobre Un Coup de Dés de Mallarmé, na sua teoria da fotografia e da obra de arte, bem como em vários momentos dos fragmentos do "Projeto das Passagens" (SELIGMANN-SILVA, 2012, p. 194). É digna de nota a confluência de Barthes com Benjamin no que concerne às fontes de reflexão escritural. Além do muito conhecido destaque da obra de Brecht e Proust no pensamento de ambos os pensadores, dentre os nomes mencionados, por Barthes, em relação à poética escritural estão, precisamente Mallarmé e Baudelaire. Sabe-se, ainda, que Barthes percorreu, também, o âmbito da fotografia e das imagens. ${ }^{5}$

É plausível destacar as afinidades do próprio procedimento de Benjamin com um princípio básico das vanguardas, a saber, a colagem,

\footnotetext{
${ }^{5}$ Ver, por exemplo A câmara clara e $O$ obvio e o obtuso
} 
entendida como "mecanismo de implosão do sistema representacionista da arte tradicional, que rompe o curso mimético da arte ao introduzir o gesto da montagem como quebra das continuidades, como espacialização escritural onde se misturam palavras e imagens" (SELIGMANNSILVA, 2012, p. 192). Nesse sentido, a obra de Benjamin problematiza as fronteiras entre a escrita dita científica, teórica e prosaica e, por outro lado, a "escritura fragmentada, opaca, ruinosa que caracteriza tradicionalmente o universo poético" (SELIGMANN-SILVA, 2012, p. 194). O mesmo notamos em Barthes, "sujeito incerto", a escrever no incerto gênero ensaio como nos diz em Aula (BARTHES, 2015, p. 56). Entre o poético, o teórico e o fragmento, ${ }^{6}$ sua obra é colocada, por vezes, sob suspeita, como foi o caso de $O$ prazer do texto. Ainda, da mesma forma que Barthes negociava escritura e transitividade em seus escritos, Georg Otte, em ensaio sobre o resto em Benjamin, nos lembra que o autor alemão se nega à mera funcionalização da palavra quando chega a afirmar sobre sua coleção de fragmentos, reunidos nas Passagens, que seu método é "montagem literária" sem "formulações espirituosas", composta de "farrapos, resíduos", sem inventariá-los para "fazer-lhes justiça da única maneira possível: utilizando-os" (2011, p. 306).

$\mathrm{O}$ aflorar da escritura é paralelo ao declínio da experiência e da faculdade de narrar sobre o qual Benjamin disserta em textos como "Experiência e pobreza" e, de forma mais extensa, em "O narrador", no qual escreve que "a arte de narrar está em vias de extinção" e nesse decorrer estamos "sendo privados de uma faculdade que nos parecia totalmente segura e inalienável: a faculdade de intercambiar experiências" (BENJAMIN, 2012, p. 2012).

A Primeira Guerra, sabemos, teve papel fundamental no que diz respeito à queda da experiência "ao submeter o homem a dominância brutal de forças impessoais da técnica, que só faz crescer e transformar nossas vidas em uma velocidade impossível de ser assimilada por palavras" (GAGNEBIN, 2013, p. 67). Como elucida Jeanne Marie Gagnebin, Benjamin evoca duas reações possíveis para a ausência de palavra comum e para o esfacelamento das narrativas (2013, p. 67). Para compensar a frieza e o anonimato social intensificados pela lógica capitalista, a burguesia busca recriar algum calor, através de um

\footnotetext{
${ }^{6}$ Como exemplo, cito: Fragmentos de um discurso amoroso, O prazer do Texto e Roland Barthes por Roland Barthes.
} 
processo de interiorização. Assim, no domínio psíquico alguns valores individuais substituem valores coletivos e a história do si vai preenchendo o lugar do comum. Benjamin situa, nesse processo, o surgimento da Erlebnis, a vivência individual. A interiorização é também espacial: "a arquitetura começa a valorizar o interior no qual o burguês escapa à despersonalização imprimindo sua marca em seus objetos" (GAGNEBIN, 2013 , p. 68). Gagnebin nos lembra do prestígio do veludo, nascido na época, o qual guarda as marcas daquele que o manuseou (2013, p. 68). Tais formulações vão ao encontro da imagem descrita por Barthes, de um indivíduo solitário encerrado em seu aposento, dedicado a uma prática da escritura já menos voltada para a exterioridade da história ou do âmbito comum.

O declínio da experiência da narração, acompanhado da emergência da prática escritural, é seguido, ainda, do surgimento do romance burguês e do individualismo a ele atrelado. Nas palavras de Benjamin, o romancista "é efetivamente o mudo, o solitário", homem "a quem ninguém pode dar conselhos, e que não sabe dar conselhos a ninguém" (2012, p. 55). É este "o primeiro indício do processo que vai culminar no ocaso da narrativa" (BENJAMIN, 2012, p. 157). Entretanto, ele ressalta, este "é um processo que vem de longe. E nada seria mais tolo do que ver nele um "sintoma de decadência"" (2012, p. 217). Para Benjamin, trata-se, antes de um sintoma "das forças produtivas seculares, históricas, que expulsam gradualmente a narrativa da esfera do discurso vivo" (BENJAMIN, 2012, p. 217). Tal perspectiva, conforme destaca Gagnebin, "ultrapassa a melancólica da nostalgia, na medida em que se atém aos processos sociais, políticos e artísticos de fragmentação para daí derivar não a simples constatação de uma situação irreversível", mas, sim, para apontar "possíveis caminhos e instrumentos para uma política verdadeiramente materialista" (2013, p. 64). Segundo Gagnebin, "O Narrador" coloca alguns marcos para "uma narrativa que saberia narrar sem se encerrar na mera vivência e sem cair na forma obsoleta da narração mítica universal." (2013, p. 71).

Ao demonstrar o enfraquecimento da experiência e sua gradual substituição pela vivência, Benjamin faz uma reflexão "sobre a necessidade de sua reconstrução para garantir uma memória e uma palavra comuns" (GAGNEBIN, 2012, p. 9). Assim, escreve Gagnebin, ele chega à ideia de que uma reconstrução da Erfahrung deveria ser acompanhada de uma nova forma de narração, isso, pois "o reconhecimento lúcido 
da perda leva a que se lancem as bases de uma outra prática estética" (GAGNEBIN, 2012, p. 11-12). É nessa via que Benjamin recorre "ao Bauhaus, o Cubismo, a Literatura de Doblin" (GAGNEBIN, 2012, p. 12). Conforme escreve Gagnebin, "essas tendências 'progressistas' da arte moderna", as quais "reconstroem um universo incerto a partir de uma tradição esfacelada", são mais fieis ao legado da "grande tradição narrativa" que as tentativas de "recriar o calor da Erfahrung a partir da vivência" (GAGNEBIN, 2012, p. 12). É assim que à antiga experiência devem opor-se formas "sintéticas de experiência", nas palavras de Gagnebin, "frutos de um trabalho de construção empreendido justamente por aqueles que reconheceram a impossibilidade da experiência tradicional na sociedade moderna e que se recusam a se contentar com a privacidade da experiência vivida"(GAGNEBIN, 2012, p. 9). Conforme escreve Gagnebin, as aporias da literatura contemporânea como "aquelas que agem em Proust", nos advertem "da necessidade de uma longa permanência perseverante nesse no man's land narrativo" (GAGNEBIN, 2013, p. 64). Nesse "no man's land" no qual se situa a obra de Proust, há um encontro de Benjamin com Barthes. Cientes das diferenças entre os dois autores, tal encontro levanta algumas questões acerca da prática escritural e da mudança histórica da narrativa. Vejamos de que forma Proust apresenta os três traços da escritura aqui mencionados, o individualismo, a materialidade da escritura e seu valor de sonho e de que forma sua obra pode lançar luz sobre a noção de escritura.

\section{Walter Benjamin e Roland Barthes, na escritura imersos}

Proust, para Barthes, está na gênese do aflorar da escritura, autor de um texto capaz "de confundir inexoravelmente, por uma subtilização extrema, a relação entre o escritor e as suas personagens: ao fazer do narrador, não aquele que viu ou sentiu, nem sequer aquele que escreve, mas aquele que vai escrever" (2012, p. 59). Para o teórico francês, "Proust deu à escrita moderna a sua epopeia" ao recusar "pôr a sua vida no seu romance e fazer da sua própria vida uma obra" (BARTHES, 2012, p. 60). Citado como figura emblemática no seminal "A morte do autor", Proust foi um dos primeiros a se posicionar contra o prestígio do indivíduo e do autor, formulações encontradas em seu "Contre Sainte-Beuve"(1999). Para Barthes, o autor é uma figura produzida pela sociedade a qual, com o empirismo, o racionalismo e a fé pessoal da Reforma descobriu "o 
prestigio pessoal do indivíduo" (2012, p. 58). Em matéria de literatura, ele escreve, foi o positivismo, "resumo e desfecho da ideologia capitalista", a conceder a maior importância ao indivíduo que escreve (2012, p. 58). Da mesma forma, para Benjamin, o autor de Recherche é valioso pois, conforme escreve Gagnebin, "realiza, com efeito, a proeza de reintroduzir o infinito nas limitações da existência individual burguesa" (2012, p. 15). A experiência de Proust, vivida, em nada se assemelha a perdida experiência comum, mas o caráter "desesperadamente único da Erlebnis transforma-se dialeticamente em uma busca universal," pois o gesto genial de Proust, como Gagnebin elucida, está em escrever não suas memórias, mas, precisamente, a busca, opondo, assim, à finitude do evento vivido, o sem limites do acontecimento lembrado (2012, p.15). Nesse percurso o autor encontra não o passado em si, mas a sua presença no presente e o presente que já estava lá, "prefigurado no passado" (GAGNEBIN, 2012, p. 15).

Benjamin vê a obra de Proust como resultado de uma "síntese impossível", composta pela "absorção do místico, a arte do prosador, a verve do autor satírico, o saber do erudito e a concentração do monomaníaco" (BENJAMIN, 2012, p. 37). Se toda grande obra excede um gênero, como o filósofo escreve, apesar do claro teor biográfico, a de Proust é "uma das menos classificáveis" (BENJAMIN, 2012, p. 37). Sua estrutura conjuga poesia e memorialística, com frases torrenciais que, como "um Nilo da linguagem", escreve Benjamin, "transborda nas planícies"; "tudo excede a norma" (2012, p. 37). A vida não é escrita como ela foi, mas sim rememorada; construída a partir do "trabalho de Penélope da reminiscência" e, nessa tessitura, o infinito do rememorado se opõe ao finito da vivência individual (BENJAMIN, 2012, p. 38). Assim, quando Proust descreve uma hora banal individual, segundo Benjamin, "ele o faz de tal maneira que cada um de nós a reencontra em sua própria existência" (2012, p.39). Seu verdadeiro interesse é o fluxo do tempo em sua forma mais real "e por isso mesmo mais entrecruzada". Assim, também, é para Barthes essa tessitura da reminiscência entre polos, uma síntese impossível: "a indecisão de Proust é profunda", ele escreve, resultando em uma forma "mista, incerta, hesitante, ao mesmo tempo romanesca e intelectual" e inspirada em autores igualmente incertos "Nerval e Baudelaire" (2012, p. 351). Todo projeto, aqui, consiste em recolher o sofrimento individual e o transcender (BARTHES, 2012, p. 352). O que Benjamin chamou de tessitura da reminiscência, para Barthes, é uma costura de fragmentos 
que formam uma sequência que "se subtrai à lei ancestral da Narrativa", e produz, "a terceira forma, nem Ensaio, nem Romance" (2012, p. 353). A estrutura dessa obra será "costurada: a obra se faz como um vestido; [...] peças, pedaços são submetidos a cruzamentos, arranjos, ajustes". "Provinda do sono", ele escreve, "a terceira forma repousa num princípio provocante: a desorganização do Tempo (da cronologia)" (BARTHES, 2012, p. 353). Subtraindo "o tempo rememorado à falsa permanência da biografia", Proust destrói a lógica ilusória da biografia que segue "tradicionalmente a ordem puramente matemática dos anos" (BARTHES, 2012, p. 353-354). Essa desorganização não é a sua destruição, na obra, numerosos elementos da vida pessoal são conservados, mas "estão desviados" (BARTHES, 2012, p. 353). Um dos desvios, segundo Barthes, é o da pessoa enunciadora, pois a obra proustiana, exemplificando neste quesito, ao lado de escritores como Mallarmé, ${ }^{7}$ um mecanismo da escritura, põe em cena um "eu"; "mas esse "eu", se assim se pode dizer, já não é exatamente um "eu" (sujeito e objeto da autobiografia tradicional): é um "'eu' de escritura, cujas ligações com o "eu" civil são incertas, deslocadas" (BARTHES, 2012, p. 355).

Segundo Carla Damião, o lastro comunitário sustenta a coesão pessoal, daí o paradoxo, como escreve Franklin Leopoldo Silvia, do declínio do indivíduo na era do individualismo, pois com a perda do comunitário "a individualidade não pode constituir-se como totalidade, terminando por abstrair-se" (2006, p. 14). A obra de Proust surge, portanto, como sintoma de um "eu" que se constitui e se dissolve na temporalidade, no movimento perpetuo entre a busca, a perda e o encontro de si na escrita (SILVA, 2006, p. 15). O resultado é, assim, uma indecisão no que concerne ao individualismo presente na escrita, o qual é colocado em cheque não só pelo contexto histórico subjacente, mas, também, pela prática escritural a qual o sujeito se dedica.

Benjamin soube inclui em sua versão do materialismo histórico outras correntes do pensamento, preocupadas, sobretudo, com um novo modo de conhecimento, como Freud, Jung, Proust e o surrealismo (DAMIÃO, 2006, p. 19-20). O mesmo movimento é claro na obra barthesiana, pois, se Marx alicerçava sua produção em o Grau zero da escrita, após 1970, claramente inspirado pela psicanálise lacaniana, Barthes pensará o sujeito não só como produto histórico-social, mas,

\footnotetext{
${ }^{7}$ Em "A morte do autor" Mallarmé é tomado como figura exemplar do mecanismo da escritura que leva ao fading do autor.
} 
também, como corpo pulsional (2005, p. 11-12). Se Barthes, distanciado da linguística e do estruturalismo propõe o retorno do autor enquanto um corpo, afastado do prestígio do indivíduo burguês, Seligmann conclui, com Benjamin, que, em Proust, o "constructo complexo de imagens e palavras se articulam em uma escritura cujo suporte é o nosso corpo como um todo e não uma abstrata 'mente"'(2012, p. 196).

Se tomo a obra de Proust como emblema da escritura é porque, como vemos na Recherche, a escritura, de um modo geral, "coloca a nu a inconsistência do sujeito, sua atopia", como uma "perturbação de linguagem", escreve Barthes, análoga "ao fading esgotante que, numa comunicação telefônica, atinge por vezes só um dos interlocutores" (BARTHES, 2003, p. 100). Tal movimento é também observado por Barthes na escrita surrealista (BARTHES, 2012, p. 60). Também para Benjamin, ao tomar a dimensão onírica, a poética surrealista deporta não só "a pequena moeda a que chamamos sentido", mas, também, o "Eu", pois "na estrutura do mundo, o sonho afrouxa a individualidade, como um dente oco" (2012, p. 23).

O sonho surge, em Proust, na estadia entre o sono e a vigília, a qual introduz uma "falsa consciência, vacilante, intermitente", enquanto "a carapaça lógica do tempo é atacada" (BARTHES, 2012, p. 353). No dizer de Barthes, assim, já não há "crono-logia", mas uma lógica da "Vacilação, da Descompartimentação" (2012,p. 353). Aberta as comportas do tempo, Barthes escreve, os fragmentos que surgem vão formar a Terceira forma da narrativa, que solapa a lógica linear do chronos.

Benjamin critica a historiografia "progressista" que leva a uma concepção equivocada do fenômeno fascista, concepção que se apoia em uma noção de tempo "homogêneo e vazio", nas palavras de Gagnebin: "tempo cronológico e linear" (2012, p. 8). Trata-se para o historiador materialista, de fundar um outro tempo, "tempo de agora", "caracterizado por sua intensidade e sua brevidade" (GAGNEBIN, 2012, p. 8). Além de sua análise da obra proustiana, o abalo da cronologia aparecerá, em Barthes, atrelado ao Neutro, ${ }^{8}$ traço presente na escritura e sustentado pela

\footnotetext{
${ }^{8}$ Conforme elucida Leda Tenório (2011, p. 33-36), o Neutro, em Barthes, é a conclusão do "Grau zero da escritura" que o teórico começou a desenvolver ainda na década de 50. Em linguística, o grau zero designa um termo neutro, por exemplo, a oposição entre os modos imperativos (que indicam injunção) e o subjuntivo (que indica o desejo ou a dúvida). O modo indicativo aparece, assim, como um modo de ausência das duas marcas. Barthes retoma essa formulação no fragmento
} 
suspensão do sentido, que leva à indecidibilidade, também chamada de significância. ${ }^{9}$ No curso sobre o Neutro, Barthes evoca o Kairos, o qual tem a potência de solapar o chronos, o fio linear do sentido e a centralidade do sujeito, mecanismo similar ao que vemos acontecer na obra proustiana.

A costura de fragmentos de Proust se aproximará, assim, da escritura uma vez que na poética escritural, como Barthes escreve, trata-se de um "escalonamento" de significantes, similar-a meu ver - a uma montagem, no qual a palavra é teatralizada e o escritor se torna o cenógrafo disperso na cena (2005, p. 13). Acrescentemos a isso a potência da escritura de fazer insinuar uma lógica temporal diferente do tempo linear e homogêneo.

Também no romancista de vanguarda Alain Robbe-Grillet, a quem Barthes dedicou três ensaios em Crítica e Verdade, veremos "uma coleção de objetos," em uma montagem que difere da escrita realista, pois o autor os escolhe entre os "menos naturais e os menos poetizáveis de uma paisagem urbana estagnada [...] e de uma vida cotidiana opaca" (TENÓRIO, 2011, p. 93). Observando essa estranha coleção, Barthes é o primeiro a notar que a proposta é fazê-los suporte de uma reflexão ótica distanciada. Tudo se passaria como se essa nova espécie de observador, lembra Tenorio, "tivesse uma luneta no lugar dos olhos, capaz de ir direta e friamente aos objetos", sem reproduzir o mito, isto é, a ideologia da pessoa (2011, p. 93). Ora, vemos este procedimento, de forma similar, também, em Proust, cujos olhos, segundo Benjamin, "os mais silenciosos e os mais absorventes" acompanham um "distanciamento intransponível" que leva Benjamin a dizer: "nunca houve ninguém que soubesse como ele mostrar-nos as coisas. Seu dedo indicador é inigualável" (2012, p. 48).

O procedimento realizado por Robbe-Grillet, para Barthes, difere do "Efeito de Real" comum à escrita de pretensão realista. Analisando o discurso histórico tradicional, o que ele chama de "historia objetiva",

\footnotetext{
“O segundo grau e os outros", de Roland Barthes por Roland Barthes (2003, p. 79), dizendo: "Eu escrevo: esse é o primeiro grau da linguagem. Depois, eu escrevo que eu escrevo: é o segundo grau". A escritura no grau zero, ele enfatiza, é anterior a essa distinção. Por isso, para literatura, o grau zero é, em ultima instância, uma impossibilidade. Todavia, é possível aproximar-se dele em determinados momentos da escritura.

${ }^{9}$ Conforme escreve Gagnebin (2014, p. 12), o leitor atento descobrirá em "O narrador" uma "teoria antecipada da obra aberta" em oposição ao sentido consolidado da narrativa tradicional. Segundo a autora, "na doutrina benjaminiana da alegoria, a profusão do sentido, ou, antes, dos sentidos", vem “de seu não acabamento essencial”. Em Crítica e Verdade (2013, p. 162) Barthes falará da literatura moderna, precisamente, como uma suspensão do sentido.
} 
Barthes dirá que o discurso histórico é, no essencial, uma "elaboração ideológica", já que a noção de fato depende sempre do sentido introduzido pelo leitor (2012, p. 176). Assim, o discurso histórico não "acompanha o real, não faz mais que significá-lo", o que se dá a partir de uma operação "bastante arrevesada" de tentar resgatar o referente sempre passado e exterior ao discurso, seguindo "o tempo res gatae" (BARTHES, 2012, p. 178). Tal configuração levará Barthes a atribuir ao discurso da "história objetiva" o mesmo dispositivo encontrado na escrita de Flaubert, a saber, o efeito de real (2012, p. 176). Como todo discurso de pretensão realista o da história dita "objetiva" conhece apenas um esquema binário referente/ significante, característica dos textos performativo, o que o leva a dizer que tal discurso histórico é um discurso performativo com trucagem. Robbe-Grillet, por outro lado, é tomado como figura do Neutro, do grau zero da escritura, da opacidade e impessoalidade, em oposição ao excesso de individualismo. O neutro, enquanto opacidade impessoal evocará, a meu ver, a imagem do vidro, que, em Benjamin, surge em oposição ao abrigo permeado por excesso de vestígios do salão burguês. Se, como lembra Gagnebin, o veludo ganha prestígio no interior do aposento burguês por permitir as marcas de quem o manuseou (2013, p.68), o vidro aparece como seu contrário, nas palavras de Damião, ele "cria o espaço onde não há rastros" (DAMIÃO, 2006). Comentando a importância, para Benjamin, do dito de Brecht "Apague os rastros", Dag T. Anderson dirá que "o lugar que nos conduz o 'apagar os rastros', é o 'ponto zero', o limiar que Irving Wohlfarth chama de "terra de ninguém"' (2000, p. 174 apud DAMIÂO, 2006, p. 60). Chegamos, assim, ao ponto zero do vidro ao lado do grau zero (neutro) da escritura, o qual nos leva a uma terra de ninguém, isto é, a um lugar de indecisão, como o "no man's land narrativo", mencionado por Gagnebin (2013, p. 64), como o lugar de permanência temporária, no qual se situa Proust, cuja obra, tomada aqui como exemplo da escritura, se situa entre o indivíduo e seu apagamento, entre o sono e a vigília, entre a palavra enquanto materialidade livre de referente e os vestígios da memória, enfim, entre a experiência verdadeira e as "experiências sintéticas".

\section{Na outra margem da escritura}

Apesar dos vários deslocamentos que sofre, a escritura jamais deixou de ser uma noção tensionada na obra de Barthes. Ainda que nasça 
do indivíduo solitário dedicado à palavra, Barthes lembra, ninguém pode "inserir a sua liberdade de escritor na opacidade da língua, porque através dela é a História inteira que se mantém" (2000, p. 9). Assim, a escritura será sempre "uma realidade ambígua"; "por um lado, ela nasce incontavelmente de um confronto do escritor com a sociedade; por outro lado, ela remete $\mathrm{o}$ escritor às fontes instrumentais de sua criação" (BARTHES, p. 15).

Contra a história entendida enquanto resgate do passado baseada na noção de progresso e tempo linear, Benjamin pensará o método materialista, inspirado, segundo Gagnebin, na estética proustiana composta pelos vestígios do passado no presente e pelo cruzamento temporal (2012, p. 16). Se Proust, usado aqui como emblema da escritura pôde servir a Benjamin, é porque, a meu ver, a escritura estabelece com o comum histórico uma relação singular.

Falar que há na escritura algo do sonho é dizer que ela é, de certa forma, o lugar de confluência dos restos diurnos, dos restos mnemônicos e do apagamento do eu frente a emergência do desejo e do inconsciente, conforme formulou Freud em seu A interpretação dos sonhos. Retornando à cena descrita por Barthes, proposta enquanto origem da escritura, é possível dizer que o trabalho de incrustação que permite transcender a ordem mimética da escrita ocorre de forma paralela à extração que subtrai a brutalidade do individualismo. É certo que nem toda escritura tem o potencial memorialista da obra proustiana. Todavia, podemos pensar que a escritura é ela mesma uma espécie de limiar, ${ }^{10}$ entre o público e o privado, o histórico e o pessoal, o sonho e a consciência. Também limiar histórico pois é lugar de permanência, o "no man's land", onde Gagnebin situa a obra de Proust. Para Seligmann a obra de Benjamin e a escritura que nela se perfila deve ser vista como um dos momentos em que "o elemento escritural recalcado", que primeiro se manifestara "em poetas e artistas como Mallarmé, Picasso e Apollinaire" vem à tona. Nessa via, Seligmann realiza um cotejamento entre a escritura de

\footnotetext{
${ }^{10}$ Em texto intitulado "Entre a vida e a morte" (2010) Gagnebin, a partir de Benjamin, define o limiar como limite e a passagem, espaço de permanência temporal variável. O limiar é o lugar do sonho, do inchaço, da intumescência, oposto aos limites rígidos da fronteira, figurando como lugar de transição entre dois territórios - como uma soleira - e que leva a uma indeterminação. Me parece plausível mencionar as semelhanças do limiar com a escritura no que diz respeito aos vocábulos a eles relacionados, "incerto", "terceira forma", o "neutro" situado entre os dois graus, a meia-vigília de Proust, o "universo incerto" de certas produções contemporâneas etc.
} 
Benjamin e aquela formulada por Derrida, pois, nas suas palavras tal escritura é, nos "termos de Derrida écrypture - escritura críptica, traço que conserva e retém algo passado", a saber, em "termos benjaminianos: uma escritura que encapsula um determinado agora (Jetztzeit)". Para Derrida, conservando em traços residuais a pessoalidade e aquilo que a transcende, há uma paradoxal historicidade na escritura, pois ainda que seja leviano em relação à História, o escritor a trata por meio de uma experiência mais viva do que a de alguns "historiadores profissionais ingenuamente preocupados em objetivar o conteúdo de uma ciência" (2014, p. 83). Trata-se, aqui, a meu ver, daquilo que Georg Otte nomeou "preciosidade dos farrapos", o valor daquilo que resta em fragmentos ricos e incertos (2011, p. 389).

Evidencia-se, assim, que, embora originada no indivíduo solitário às voltas com a palavra, a escritura, dada ao mesmo tempo como sonho e como ameaça, pode escapar, sempre em graus variados, o âmbito da vivência pessoal, lançando o leitor na indecidibilidade, como em um limiar, oposto à rigidez das fronteiras.

\section{Referências}

BARTHES. Roland. Sur la littérature. Paris: Universiteire de Grenoble, 1980.

BARTHES, Roland. O grau zero da escrita. Tradução de Mário Laranjeira. São Paulo: Martins Fontes, 2000.

BARTHES, Roland. Variations sur l'écriture. In: Complètes: Tome IV: 1972-1976. Paris: Seuil, 2002. p. 268-280. . Oeuvres

BARTHES, Roland. Roland Barthes por Roland Barthes. Tradução de Leyla Perrone- Moiséd. São Paulo: Estação Liberdade, 2003.

BARTHES, Roland. Sade, Fourier, Loyola. Tradução de Mário Laranjeira. São Paulo: Martins Fontes, 2005.

BARTHES, Roland. A câmara clara. Tradução de Júlio Castañon Guimarães. 3. ed. Rio de Janeiro:Nova Fronteira, 2011.

BARTHES, Roland. A morte do autor. In: . O rumor da língua. Tradução de Leyla Perrone-Moiséd. São Paulo: Martins Fontes, 2012. p. 57-63. 
BARTHES, Roland. Durante muito tempo, fui dormir cedo. In: . $O$ rumor da língua. Tradução de Leyla Perrone-Moiséd. São Paulo: Martins Fontes, 2012. p. 348-363.

BARTHES, Roland.O discurso da História”. In: . O rumor da língua. Tradução de Leyla Perrone-Moiséd. São Paulo: Martins Fontes, 2012. p. 163-180.

BARTHES, Roland. Crítica e verdade. Tradução de Leyla PerroneMoisés. 3.Ed. São Paulo: Perspectiva, 2013.

BARTHES, Roland. O óbvio e o obtuso. Tradução de Isabel Pascoal. Almedina: Edições 70, 2015.

BARTHES, Roland. Aula. Tradução de Leyla Perrone-Moisés. São Paulo: Cultrix, 2015.

BENJAMIN, Walter. Obras escolhidas. v. 1: Magia e técnica, arte e política. Tradução de Sérgio Paulo Rouanet. 8. ed. revista. São Paulo: Brasiliense, 2012. p. 37-50.

DAMIÃO, Carla Milani. Sobre o declínio da “sinceridade”. Filosofia e autobiografia de Jean-Jacques Rousseau a Walter Benjamin. São Paulo: Edições Loyola, 2006.

DERRIDA, Jacques. Essa estranha instituição chamada literatura: uma entrevista com Jacques Derrida. Tradução de Marileide Dias Esqueda. Belo Horizonte: Editora UFMG, 2014.

FREUD. Sigmund. [1900]. A Interpretação dos Sonhos. Rio de Janeiro: Imago. 2006. v. IV.

GAGNEBIN, Jeanne Marie. Prefácio: Walter Benjamin ou a história aberta. In: BENJAMIN, Walter. Obras escolhidas. v. 1: Magia e técnica, arte e política. Tradução de Sérgio Paulo Rouanet. 8. ed. revista. São Paulo: Brasiliense, 2012. p. 7-19.

GAGNEBIN, J.M. História e narração em Walter Benjamin. São Paulo: Perspectiva, 2013.

OTTE, Georg. A preciosidade dos farrapos. In: MIRANDA, Wander Melo; SOUZA, Eneida Mária de (Org.). Crítica e coleção. Belo Horizonte: Editora UFMG. 2011. p. 289-307. 
PERRONE-MOISÉS, Leyla. Com Barthes. Rio de Janeiro: Martins Fontes, 2012.

PROUST, Marcel. Contre Sainte-Beuve. In: Marcel Proust on art and Literature. New York: Carroll \& Graf, 1997. p. 19-265.

SELIGMANN-SIVLA, Márcio. Walter Benjamin e os sistemas de escritura. Disponível em: http://taurus.unicamp.br/bitstream/ REPOSIP/118306/1/ppec_8636165-5828-1-PB.pdf >. Acesso em: maio 2018.

SILVA, Franklin Leopoldo e. Prefácio: Sobre o declínio da "sinceridade". Filosofia e autobiografia de Jean-Jacques Rousseau a Walter Benjamin. São Paulo: Edições Loyola, 2006. p. 11-18.

TENORIO, Leda da Motta. Roland Barthes: uma biografia intelectual. São Paulo: Iluminuras, 2011.

Recebido em: 7 de outubro de 2018 Aprovado em: 8 de novembro de 2018 